\title{
“Touch” by Abburi Chayadevi
}

\author{
TRANSLATOR'S NOTE AND TEXT
}

This short story in precise and elegant Telugu prose comes from the contemporary writer Abburi Chayadevi's outstanding collection Her Own Way (Tana mārgam). A highly individual voice in modern Telugu, Chayadevi writes with restraint about the nuances of feeling and awareness in modern, mostly middle-class Telugu families. Born in the Godavari delta in 1933, she created a niche for herself as a feminist writer at a time when feminist sensibilities were only beginning to take shape in Telugu. She published several collections of powerful short stories, a novella, and a set of children's stories. She died in 2019.

\section{“TOUCH” BY ABBURI CHAYADEVI}

When I went in, Father was lying on a cotton mattress, facing the wall. Since I left my sandals at the door, I made no sound of any kind. I approached the cot and said, "Sleeping?"

"Who's that?" He turned toward me.

"It's me."

"Come sit here," he said, still lying flat. I started to drag a steel chair to that side, and he heard the noise and said, "Why so far away? Come, my dear, sit close to me." He raised himself to a sitting position and, tapping the cot with his hand, pointed to a place near him.

I sat down on the cot's wooden frame.

Groping with his hands, Father touched my back. He patted the cot and said, "Sit up."

I shifted slightly away from him, finding my place.

He was feeling around with his hands; he found my hand and held it between his. "I've been expecting you every day. Are you all right?"

"Um," I said, softly.

He said nothing more. He went on caressing my hand in silence. 
Once, a while back, that is, when I was already old enough to get married, he and I were going somewhere together in a rickshaw. Although there was plenty of room, I sat there, shrinking well away to one side.

"Sit up straight," Father said, "you could fall out."

With some hesitation, I moved an inch closer to him.

When I was learning to read, he would usually speak to me from a certain distance as he drilled me in the letters, or out of concern for ritual purity, signaling to me with his eyes. I didn't dare come too close to him, to assume too great a familiarity. Whenever I saw him, I felt like I should take a bath and put on freshly washed clothes; I would fold myself into myself, and this became a habit. So how could I sit close enough to touch him in that rickshaw?

When we kids would come home from school, he would bring us close and question us about this and that, and the kids would tell him the news, like parrots. Not only that, he would be standing there on the threshold, glowering at us, scowling, asking: "What marks did you get in arithmetic? Did you bring me the mark sheet?" All of us were terrified of him. I lived with that terror to the age of twenty. Even now, fear hasn't left me.

Father is now past eighty. Too old to have an operation to restore his sight. Though in other areas his health is good, the loss of his sight has rendered him helpless. For the last two years he's been in bed.

When we heard that my mother-in-law was not well, we took leave and came to spend a few days with her. Whenever I'm in town, somehow or other I make time to see Mother and Father. I sit and talk with him for half an hour and leave.

I still have a childhood memory of sitting close to Father, of being close. Now, when he took my hand in his and touched me lovingly, I remembered how, ever since my childhood, in my innermost heart I'd ached for his touch. I could see it all clearly before my eyes, and tears welled up. When I tried to speak, I choked. Would he ever know how much I once yearned for his loving touch?

Was it because of his distant dignity and his fierce glances that the flood of love flowing between us in our letters evaporated when we met? Ever since I was a child, I couldn't cope with his eyes, which burned like the rays of the sun. Since I couldn't bear them, I avoided them. This, too, became a habit. Why can't I come close to him now, though I know that his eyes are like burnt-out lamps?

The first time I came from my town and sat down on the edge of his cot, I noticed bugs were crawling on it. I caught one or two and silently threw them under my feet and crushed them.

After that, whenever a bug would turn up in our house, on the bed, my husband would get upset. I'd say that maybe it got there because it somehow got into my clothes when I was sitting on Father's cot. So whenever I was about to set out to visit Father, my husband would caution me not to sit on the cot but to stay on a chair at some distance from him as we talked.

But if I moved my chair away and was about to sit down, Father would say: "Come sit closer." How could I refuse? He would not be satisfied until I was leaning against him, with my hand in his. 
All his life my father yearned to have sons, but in the end only we girls remained. In the final stage of his life, there was one son who was like a strong tree holding up the whole family; he died. If you say the word "fate," I guess that's what it means. After my brother's death, I hesitated even to go see Father-as if some notion that I'd made a mistake was pulling me back. I wanted to hold him tight and say, "Don't cry, I'm here for you." But I was afraid to touch him. That was how he'd brought me up.

After we'd been sitting and chatting for a little while, he asked me to trim his fingernails and toenails. There was no point in even mentioning such things to Mother; she had her hands full. It would be like the mortar, struck by one hand, complaining to the drum that was pounded by two hands on either side. I couldn't ask my brother; he's no more. His kids lived somewhere else. No way to ask my sister-in-law. Maybe he'd asked me because he ached to have me perform some such service. It was a gift. I trimmed his nails carefully, with great joy.

I think Father's mind was not at peace. Caressing my hand, he said, "It would be good if you were to move to this town, I would come stay with you." I looked at him helplessly. He couldn't see my eyes. My words brought him no comfort.

Father asked nothing more. Silently, he went on caressing my hand as he sat on the bed. At that moment, all my studies, my job, everything-all seemed to me like mere window dressing. I sat there a little while more, then I stood up and said goodbye.

Father's soft touch seemed to follow me as I was going home in the rickshaw. My eyes filled. The road ahead turned dark.

\section{HOW TO TOUCH “TOUCH”}

\section{Gautham Reddy (Near Reader)}

As a story, "Touch" is rather uneventful, describing little more than a half-hour visit. A daughter takes a seat near her father, exchanges a few pleasantries, clips his fingernails, and takes her leave. The setting features little more than an old wooden cot, a steel folding chair, and a few pesky bugs. These events are narrated in a colloquial style that is marked by a conspicuous minimalism. Yet within this austere frame, Abburi Chayadevi weaves together a series of highly evocative memories and reflections that illuminate the tremendous feelings of loss and helplessness that result from a daughter's confrontation with her father's vulnerability and mortality. In this regard, the simple everyday language of the story poignantly reveals the protagonist's struggle to express the great depth of her emotion, grief, and sense of connection with her father.

The story opens with the daughter announcing, "It's me," as she takes a seat next to her blind father's cot. Her father questions the distance she has set between them and insists that she join him on his cot. Taking her hand in his, father and daughter sit together in silence. The daughter's mind wanders to memories of her father and the distance that has always existed between them. This distance, a mark of respect as much as a habit of fear, structured her interactions with her 
father from her earliest years. As the daughter's recollections suggest, this was a distance that permeated all aspects of their relationship but was articulated primarily through physical touch. There are two ways readers can make sense of the "distance" between father and daughter. The first, a direct and more existential reading, offers itself through the first-person perspective of the daughter as she narrates her experience of distance through memory and personal reflection. The second, an indirect and more sociological reading, emerges through the ways distance has been formally encoded into the father-daughter relation through Telugu social norms and cultural expectations.

Let us begin with the first existential reading. The daughter recalls that, during her younger years, the mere sound of her father's voice or the sight of his piercing gaze was enough to make her instinctively shrink. A stern disciplinarian, the presence of her father inspired a "terror" that she would live with until she was twenty years old. Even as an adult, when practical circumstances such as sharing a seat in a rickshaw demanded proximity, the daughter found herself retreating to the seat's edge, risking falling out of the vehicle rather than infringing upon her father's presence. The daughter's terror, we gradually understand, was not born of an apprehension of danger or violence, but rooted in a desire to honor a person she understood as occupying a role of great dignity and prestige in the home. It was a fear that acknowledged the reality of a parental role considered sacrosanct, born of a deep respect coinciding with love and admiration. The daughter remembers how she ached for her father's touch as a child-for a gentle pat on the back, a stroke of her hair, to fold her hand in his-but that his formidable presence precluded any of these familiar gestures as everyday forms of affection. In later years, when she was older and had left her childhood home, she forged a closer more familiar connection with her father through an exchange of letters. Yet this disembodied flow of intimacy "evaporated" whenever she returned to visit him in person. Even now, though he was past eighty, blind, and bedridden, she found herself still hesitating to approach him. When her father asks her why she hasn't visited more frequently, she becomes tongue-tied, unable to mumble little more than a helpless "um."

Touch is a proxy for all the forms of distance that have grown between daughter and father, for the way they hold her hostage and prevent her from knowing or reciprocating the love she seeks. Her father, his piercing gaze eviscerated with age, now looks for his daughter's touch and freely offers his-we see him affectionately clasping her hand, requesting her to sit near him, and asking her to perform the highly intimate act of cutting his nails. Yet as the distance between them has diminished over the years, so too has the cherished hallowed image of her father as a powerful and capable authority, the very image that necessitated and maintained the distance between them. The father's open approach to his daughter, a sign of his growing vulnerability, disrupts the daughter's knowing of her father. She suddenly finds herself at a loss to understand her inability to draw closer to her father. 
Though flooded with feelings of love and concern for him, she chafes against the great barrier of history, unable to offer him the warmth or connection he desires and needs. Burdened by a feeling of estrangement, the daughter's memories and reflections on the nature of this distance are thickened by a painful sense of helplessness and despair. She sees that her father now needs her, that he aches for her touch as she once ached for his. And yet, although the vulnerability of her father has opened up a possibility for a new type of intimacy, the daughter does not feel she can engage with him in the way they both long for. She was "afraid" to touch him; as she explains, "That was how he'd brought me up." And as she admits this, a feeling of inevitability emerges, a resignation that this distance has not only been unassailable but unavoidable.

Now let us turn to the second, sociological reading. Even as the daughter draws us into a web of private memory and reflection, we are also exposed to some of the greater social and cultural realities that structure her world of feeling. Through casual references and subtle details, a dark portrait emerges of the powerful ways the conventions of caste and patriarchy have determined the possibilities of intimacy between daughter and father.

As in many upper-caste Hindu homes of the mid-twentieth century, concerns around ritual purity determined the degree of familiarity that was acceptable among members of the daughter's family. One of the reasons her father maintained a physical distance from her was to avoid "pollution." The daughter acknowledges that she was instilled with an anxiety around ritual purity from a young age, aware that her mere touch could jeopardize her father's piety. While young children were not in and of themselves considered "polluting," their inability to recognize sources of pollution meant that they were often at risk of contracting and then spreading impurity. The daughter remembers how her father would fastidiously preserve his distance from her potentially polluting touch as he taught her the alphabet, speaking cautiously from afar and signaling with his eyes. As a result of such constant vigilance, a stiff sense of formality and a preoccupation with cleanliness were instilled in the daughter as forms of deference and respect. Ever alert to caste considerations of ritual purity, she notes that as a child, "Whenever I saw him, I felt like I should take a bath and put on freshly washed clothes." As the daughter grew older, taboos and cultural associations of uncleanliness around menstruation would have intervened and increased the distance between father and daughter. In the ritual universe of Brahminical life, a woman's touch was believed to be intrinsically impure during menstruation. As such, it was customary in upper-caste households to sequester women on their period from participating in cooking, domestic chores, and family life for several days as a means of quarantining the menstrual dangers of ritual pollution from "clean" members of the household.

While there is only one direct reference to caste and the considerations of ritual purity in the daughter's narrative, there are several references to the patriarchal 
limits of Telugu society that conditioned the daughter's sense of self and her relationship to the men in her life. Once daughters married out of their childhood homes, they were deemed strangers to their parents and male siblings in many social respects. Until relatively recently, Telugu families were organized along the joint family system that followed the male line. This meant that while sons were expected to stay at home and provide for the welfare of the family and its elders, daughters were expected to marry outside the family and integrate into their husband's households. In this regard, the distance between father and daughter was structured by the social protocols that dictated the relationship of daughters to their natal home. After their marriage, daughters were expected to disidentify and distance themselves from their childhood home and family. We see this informing the way the daughter imagines her visits to her father after her own marriage. She frames such visits as originating in "my town," by which we are to understand the town she lives in with her husband. This suggests that she now entirely identifies her home, town of origin, and family with her husband. Consequently, the daughter does not conceive of her visit to her father as coming home or a return to her ur (native place), as a son who has left his childhood home might, but as a polite social engagement carried out in a less familiar place.

Throughout the daughter's narrative, we see that she was expected to orient her primary social obligations and affections first and foremost to her husband and his extended family network. In fact, even the purpose of her present visit was in relation to her husband's family. She mentions that she had actually arrived to the town of her childhood in order to accompany her husband on a visit to his sick mother and not, as it initially seemed, to pay her respects to her father. In the daughter's social world, visits to her own parents and hometown were not a priority. It was a conventional idea that women who visited their natal homes too often were considered to be negligent in their duties as a wife, daughter-in-law, and mother. As the daughter herself remarks, "Whenever I'm in town, somehow or other I make time to see Mother and Father." It is with great effort that the daughter is able to excuse herself, "somehow or other," during such visits to her husband's family in order to attend to her own sick father. We may infer that her husband did not accompany her on such excursions and that the daughter's time away from her husband's family on trips "home" was perceived as something of a personal indulgence not only by the husband's family but also by the daughter herself. In consequence, the daughter's visits to her father were infrequent and limited to little more than "half an hour."

As in most Telugu families, the daughter recalls that her father "yearned to have sons." A son would have provided her father with a sense of security and been responsible for his care during his old age. The daughter remembers her brother, the family's sole son, as a proud man "who was like a strong tree holding up the whole family." Her brother's untimely death during the prime of his life not only wreaked the devastating loss of a child for her father, but the loss of the family's 
security and sense of future. With no other sons, the daughter's father and mother were left to fend for themselves in a highly vulnerable financial and social position. During rare visits to her parents, the daughter is pained to discover insects crawling over her father's bed, shocking signs of the negligence and decrepitude that had entered into a home once marked by its concern for purity and hygiene. The daughter's own commitments to her husband and his family meant that she was unable to take an active role as caretaker or provider in her father's life. The daughter's visit concludes with a simple appeal from her father, "It would be good if you were to move to this town, I would come stay with you." In a social context where daughters could not freely spend more than a half hour with their parents, the father's impossible request is emotionally stirring. His words highlight the daughter's inability and unwillingness to transgress her social and personal obligations to her husband's family. In this regard, the distance between father and daughter has become permanent and insurmountable.

In a field of literature historically dominated by men, Abburi Chayadevi invites us into the interior realms of Telugu women. Set within the confines of an uppercaste and middle-class Telugu home, "Touch" is a powerful short story that highlights the range of anxieties and emotions that accompany a married woman's visit to her elderly father. It contains unmistakably autobiographical elements and reflects Chayadevi's own strained relationship with her father. Born in family of orthodox Brahmins in Coastal Andhra, she spent most of her professional life away from her father working as a librarian based in New Delhi. As a child, Chayadevi recalls that she was discouraged from writing by her father and chafed under his strict authoritarian personality. Father-daughter relations are a reoccurring theme in Chayadevi's work and she later published a short novel entitled Mrityunjaya (1993) based on letters exchanged with her father.

Chayadevi achieved renown as a short-story writer during the mid-twentieth century, a period when women were first beginning to emerge as a powerful new voice in Telugu literary life. She published short stories and poetry in popular periodicals, served as an editor of a women's monthly, and compiled several collections of contemporary poetry. Today, Chayadevi is considered a forerunner of feminist writing that challenged upper-caste gender norms and her work was included in the landmark anthology of Telugu feminist poetry, Nili Meghalu (1993).

Here, however, Abburi Chayadevi's "Touch" stands on its own, providing a powerful glimpse into the nature of many father-daughter relationships in contemporary India. Chayadevi artfully explores existential aspects of universal human themes relating to childhood, aging, and mortality through the sentiments of a child who is confronted by the vulnerabilities of her aging father. At the same time, her universalist meditation is situated within the particularities of gender and caste and foregrounds the patriarchal values that constrain the affective horizons of modern Telugu women. Saturated by a sense of deep despair, "Touch" leaves the reader haunted and unsettled by a sense of things that could have been but never will be. 
“DON'T STAND SO CLOSE TO ME!": REMARKS ON CHAYADEVI'S “TOUCH”

\section{Sanjay Subrahmanyam (Far Reader)}

Touching and distance are a part of everyday preoccupations for many Indians, especially those who belong to the upper castes. This can seem a paradox. If you have ever stood in a line to buy a train ticket, or taken public transportation in India, you will know that people press on you constantly, eating away at any notion of a comfortable distance, even when it is extremely hot and humid. For a woman, this can turn into a not very subtle form of harassment. If you push away, or express your discomfort, you risk being taken for a snob or a disagreeable person. Analysts of crowd behavior have even suggested that this too-close proximity may in part be responsible for the stampedes and deaths that happen periodically in contemporary India in the great fairs, festivals, and such, from the Kumbh Mela to the Mahamakam festival in Kumbakonam. But when one turns away from these public spaces to the interior of the household, things can change rapidly. Again, matters are far from simple. Space in many households is desperately limited, and so too is any notion of separation or privacy. Many married Indian couples must find intimacy in the most difficult and surreptitious of circumstances then, with siblings, in-laws, and others constantly breathing down their necks. This of course generates a certain quantity of bawdy humor on the one hand, but also results in deep tensions that few are willing to talk about, let alone properly analyze or dissect.

Abburi Chayadevi's short story addresses this question of touching and distance at a more metaphorical level, from the point of view of a young or middleaged woman who is visiting her elderly and ailing father. Past eighty, the once formidable father has lost his sight and is confined to a small and somewhat dirty room, lying on a wooden bed crawling with bugs. She, like the other characters, is given no name; everyone is referred to simply in terms of their familial relationships: "father," "mother," "brother," "husband." The woman, who is well-educated and has a job, has moved to another town with her husband, and so she sees her father infrequently now. After she enters the room, the father insists that she come closer, and holds and caresses her hand. This leads to her remembering many other moments in her upbringing, when such closeness and intimacy would have been wholly inconceivable. In earlier years, before his illness, the father had insistently kept his distance, ostensibly because of concerns with ritual purity. With his "fierce glances," he instilled a sense of shame in his daughters, to the point that they almost felt dirty in his presence, as if they "should take a bath and put on freshly washed clothes." It is implied however, that earlier still, perhaps when they were infants, they did once enjoy a greater physical closeness, if only for a short while.

The whole relationship between father and daughter is characterized by an oppressive tension. The father would have preferred sons rather than daughters, but has had to make do with what he had. The one son he had counted on died 
early, and the son's family is now indifferent to the old man. There is a sense that finally, in holding and caressing the daughter's hand, and insisting that he would gladly move in with her and her husband if he could, the father is clutching at straws. The gestures are at last there, rather too little too late, for a deeper and more real affection seems absent. The daughter tries to console herself in small tasks such as trimming the father's nails, but it seems that she too is just seeking some meager consolation for missed past opportunities rather than living in the moment.

The tension between father and daughter is, as noted in the contribution by Gautham Reddy, a theme that has been visited earlier in Chayadevi's writings. The father who withholds his affection is of course a classic modern figure, of which the most striking instance may be Hermann Kafka, who apparently ensured (in Saul Friedländer's words) that his son Franz "felt humiliated and shamed" by him. ${ }^{1}$ But unlike in Kafka's The Metamorphosis, here it is the father rather than the child who has been transformed, not by becoming a bug but by being surrounded by bugs. In his lectures on Kafka, Vladimir Nabokov tried to bring the skills and cold gaze of an amateur entomologist to render the transformation anodyne, but the truth is that the reader is meant to feel both sympathy and revulsion for Gregor Samsa. ${ }^{2}$

Underlying all this is a deeper problem with touch, distance, and cleanliness. One is given to understand by Chayadevi that these preoccupations look different to men and women, with the former being far more conservative in the face of the challenges of modernity and its threat to bridge distances that had previously been unbridgeable. For, now that the father is ailing, it is the daughter's husband who has taken over his role as the guardian and guarantor of distance and cleanliness. From a safe distance, he advises his wife not to sit too close to her father when she visits, out of fear that she be contaminated by him and the bugs on his cot. Ironically, blindness has made the old man indifferent to the obsessions that characterized his attitudes before; but these have simply been passed on as obsessions to someone else-another man, of course.

The short story has no clear spatial location, and could also be taking place at any time over the last half-century, with only a few direct markers such as the young woman's education and job, and the presence of a steel chair, suggesting that this is probably in a small town in post-Independence India. But it is certainly a time when the old ways regarding touch, distance, and purity were gradually being questioned. As a child in a Tamil Brahmin family, growing up in the 1960s, I can recall the complications that these old ways posed to us. (It may be noted that Chayadevi comes from a Brahmin background in coastal Andhra.) Our parents considered themselves "modern," and had stepped away from many of the older ideas. We directly sipped water, juice, and tea from cups and glasses, rather than pouring them into our mouths from a safe distance above. We had become just a little bit careless about using our left hands at the table. Ideas of eccil, or pollution through saliva, were still familiar to us, but meant much less than they used 
to. And so on. But whenever we left Delhi to visit our extended family in South India, or spent time with the older generation, our behavior would become the subject of reproach. We did not easily understand, for example, why at certain moments people observed madi, a form of ritual purity which meant that you could not touch them, say between the time they had their bath and finished their rituals and prayers in the morning. For an extended time, an old widowed aunta former child widow with a shaven head, who wrapped herself in a single piece of white cloth-lived with us and observed an even more complicated set of such rules. With her and others of her ilk, there were lots of other prohibitions and regulations regarding food, leftovers, and so on. Indeed, food was nothing short of a mania in this world; one talked endlessly about it, spent inordinate amounts of time preparing it, and it became an area where for women like this widowed aunt, sensuality (largely blocked from other obvious spheres) effectively came to be sublimated. To be sure, infants were largely exempted from the rules and proscriptions that applied to others. But as one grew up, things became far more convoluted, especially for women. Again, in some of the distant parts of the family, people still observed older rules concerning the segregation of women during menstruation, or at least their exclusion from the kitchen. Some of my female cousins, who came from "modern" families, were deeply shocked by radical versions of this when they married into traditional families in Thanjavur or Tiruchi even within the same Brahmin subcaste.

I do not see in Chayadevi's story a simple tension between a more traditional father and a more modern daughter, although I suppose that reading is certainly permissible. In a variety of ways, often having to do with the movement of people, modern India does cast a shadow on this kind of parent-child relationship. But for me, the story is largely about fathers who prefer sons to daughters and starve their female children of affection, in a way that certainly had a different meaning in the second half of the twentieth century than it might have had a century earlier. At the same time, it seems to me (both from personal experience and from observation) that some habits regarding distance persist even across the so-called modern-traditional divide. Despite his assertive modernity in some matters, my own father maintained a marked physical aloofness with his children once they had left infancy. However, unlike Chayadevi's female protagonist, none of his children (whether female or male) necessarily felt a great sense of deprivation at this, perhaps because we came to internalize such attitudes, and perhaps because we also realized that this did not have to do with a lack of affection. Unlike our European friends, many Indians of my social background and generation do not (and did not) find it distressing if couples do not make ostentatious gestures of affection in public, or if family members do not embrace when they meet or say goodbye. Old habits die hard, and this is especially so when the habits are deeply inscribed in the body. The touch and its deeper significance remain mysterious, yet full of meaning. 